\title{
Future therapeutic strategies for metastatic prostate cancer
}

\author{
Minke Smits ${ }^{1}$. Winald Gerritsen ${ }^{1} \cdot$ Niven Mehra ${ }^{1}$ \\ Published online: 9 September 2019 \\ (c) The Author(s) 2019
}

\begin{abstract}
During the last decade several new therapies have been investigated and approved for metastatic prostate cancer that greatly impacts patients' quality of life and outcome. Nevertheless, optimal sequencing algorithms are still lacking, as are combinatory strategies that deliver long-term disease stabilization. Precision medicine, utilizing molecular profiles from tissue biopsies, will help us deliver optimal patient care by identifying patients that may benefit from targeted- and immunotherapy, and help guide treatment decisions by use of predictive biomarkers. Here, we present an overview of predictive biomarkers in prostate cancer, including mismatch repair and DNA damage repair deficiency, and promising novel targeted- and immunotherapies regimens, such as PSMA-radioligand therapy, PARP inhibition and PD-1/PD-L1 and CTLA-4 checkpoint therapy. We anticipate that these agents in monotherapy and in combination regimens will alter uro-oncological patient management within the next ten years.
\end{abstract}

Keywords $\mathrm{mHSPC} \cdot \mathrm{mCRPC} \cdot \mathrm{immunotherapy} \cdot$ targeted therapy $\cdot$ PSMA-ligand therapy $\cdot$ molecular profiling

\section{Samenvatting}

In de afgelopen jaren zijn nieuwe vormen van therapie onderzocht en geregistreerd voor gemetastaseerd prostaatcarcinoom, die een enorme impact hebben gehad op de kwaliteit en kwantiteit van leven van patiënten. Echter, een optimale behandelingsstrategie ten aanzien van de volgorde van therapie en de combinatie van verschillende therapieën, die langere stabilisatie van ziekte kunnen bewerkstelligen, ontbreken nog. Het verkrijgen van een moleculair profiel van kanker door middel van het nemen van biopten helpt bij de identificatie van de patiënten die baat hebben bij targeted en immunotherapie en bij de selectie van andere behandelstrategieën door het gebruik van predictieve biomarkers. In deze review geven we een overzicht van predictieve biomarkers, zoals mismatch-repairdeficiëntie en DNA-repairdeficiëntie en veelbelovende nieuwe therapieën, zoals PSMA-ligand therapie, PARP-remmers en immunotherapie. Deze behandelingen zullen zowel als monotherapie, als in combinatieschema's hoogstwaarschijnlijk onze uro-oncologische zorg in de komende tien jaar veranderen.

Trefwoorden $\mathrm{mHSPC} \cdot \mathrm{mCRPC} \cdot$ immuuntherapie $\cdot$ targeted therapie $\cdot$ PSMA-ligand therapie $\cdot$ moleculair profileren

\section{Introduction}

During the last decade several new therapies have been investigated and approved for metastatic hormone sensitive (mHSPC) and both metastatic and non-metastatic castration resistant prostate cancer (mCRPC and nmCRPC); these include docetaxel and cabazitaxel, androgen receptor (AR) signaling inhibitors (e.g. abiraterone, enzalutamide,

Niven Mehra, MD, PhD

niven.mehra@radboudumc.nl

1 Department of Medical Oncology, Radboud University Medical Center Nijmegen, Nijmegen, The Netherlands apalutamide and darolutamide), and radium-223 for bone predominant mCRPC. Although these new palliative therapies have had great clinical impact on patient quality of life and outcome, optimal sequencing and combinatory strategies are still lacking, as well as introduction of new (immunotherapeutic) treatment strategies that may deliver long-term disease stabilization.

Here we present an overview of new therapies which have been evaluated or are currently under investigation in mHSPC and mCRPC and we discuss novel and innovative treatment strategies that may be introduced into the therapeutic landscape of metastatic prostate cancer within the next ten years. 


\section{Immunotherapy}

There are several ongoing immunotherapeutic trials for patients with localized high-risk HSPC, oligometastatic HSPC, mHSPC and mCRPC. Immunotherapy may boost any shortfalls that may occur in any stage of the tumorimmunity cycle [1], and comprises a heterogeneous group of agents. Neoantigens generated during the process of oncogenesis and tumor evolution may be presented by dendritic cells to immature T-cells in lymphoid organs, resulting in priming and expansion of tumor-specific T-cells. Vaccination strategies enhance neoantigen load for antigenpresentation, whereas dendritic cell vaccination strategies increase antigen-presentation capacity. Following migration of cytotoxic T-cells into the tumor environment, they bind to MHC molecules presenting specific antigens on target cells to eliminate cancer cells. Immunogenic cell death drives presentation of additional neo-antigens that may further stimulate the cancer-immunity cycle. In prostate cancer, several steps of this cycle are known to be hampered due to a high level of immunosuppression present in the tumor micro-environment (TME) [2, 3].

In the last decade several treatment strategies have been developed specifically interfering with one or more steps of the cancer-immunity cycle, such as DNA vector vaccines, cellular vaccines, adoptive T-cell therapy, and checkpoint therapy. Many strategies have also been investigated in prostate cancer and will be discussed below.

\section{Vaccination}

Several different types of vaccines were investigated in mCRPC; cell or vector-based vaccines, including PROSTVAC and GVAX, and dendritic-cell based vaccines, including sipuleucel-T. For mHSPC, most studies on vector or cellular vaccination have yet to be published.

\section{Natural dendritic-cell vaccines}

In 1994 it was discovered that dendritic cells (DCs) could $e x$ vivo be generated from monocytes by culturing them in the presence of IL-4 and GM-CSF [4]. However, the DC function was negatively affected probably by the long culture period and the addition of compounds required to differentiate them into DCs. During the last decade it has been discovered that natural DCs (plasmacytoid and myeloid DCs) can easily be obtained by leukapheresis without the need of culturing and several clinical trials are demonstrating its safety and effectiveness $[5,6]$.

Several small studies have been conducted to investigate whether monocyte-derived DCs can be used to evoke or enhance tumor-specific immune responses [7-9]. Although immune response was often observed, these did not always translate into clinical meaningful responses in patients with prostate cancer. Presumably, the presence of high levels of immune suppressive cells in the tumor microenvironment, such as myeloid-derived suppressor cells (MDSCs), prevented full activation of the induced $\mathrm{T}$ cells. To overcome these potential suppressive factors co-administration of docetaxel chemotherapy with DCs was investigated in mCRPC, since taxanes were shown to decrease MDSC levels in murine models [10]. This randomized phase II trial compared docetaxel in combination with monocyte-derived DCs to monotherapy docetaxel. Although no difference was seen in progression free survival (PFS) and disease specific survival (DSS), a significant decline of MDSCs was observed in patients who received docetaxel and DCs, which appeared to be an independent prognostic factor for DSS [11]. A phase III trial (NCT02111577) is ongoing investigating overall survival (OS) in docetaxel with DCs versus monotherapy docetaxel. The disappointing results in earlier trials could possibly also be explained by the use of monocyte-derived DCs instead of natural DCs. The immunologic efficacy and clinical response of natural DCs tested in a Dutch randomized phase IIa trial (NCT02692976) in first-line patients with $\mathrm{mCRPC}$ will be presented this year.

\section{Sipuleucel-T vaccination}

Prostatic acid phosphatase (PAP) is expressed in the epithelial cells of the prostate, and was discovered in 1936 by Gutman before the introduction of prostate specific antigen (PSA). Its expression is increased in prostate adenocarcinoma, making it an interesting antigen for vaccination strategies. Sipuleucel-T is a therapeutic vaccine consisting of CD54-positive monocytes directed in vitro into activated antigen-presenting cells by short-term culture with PA2024, a fusion protein of PAP and granulocyte macrophage colony-stimulating factor (GM-CSF) [12]. The clinical effects of sipuleucel-T were investigated in several phase III studies, and while PFS endpoints were not met, the pivotal phase III registration study powered for OS benefit was a positive study [13-15]. Proliferation of T cells directed against PAP and PA2024 was more often seen in patients receiving sipuleucel-T, with a positive relationship between antibody titers and the duration of OS [15]. Based on these studies sipuleucel-T was FDA-approved for asymptomatic or minimally symptomatic mCRPC in 2010 and EMA-approved in 2013. It was withdrawn by the EMA in 2015 requested by the marketing authorization holder for commercial reasons. Many trials are testing Sipuleucel-T together with regimens that may boost neo-antigenicity (radium-223, taxanes, PARPi) and immune checkpoint-inhibitors, and are discussed further in the future perspectives section. 


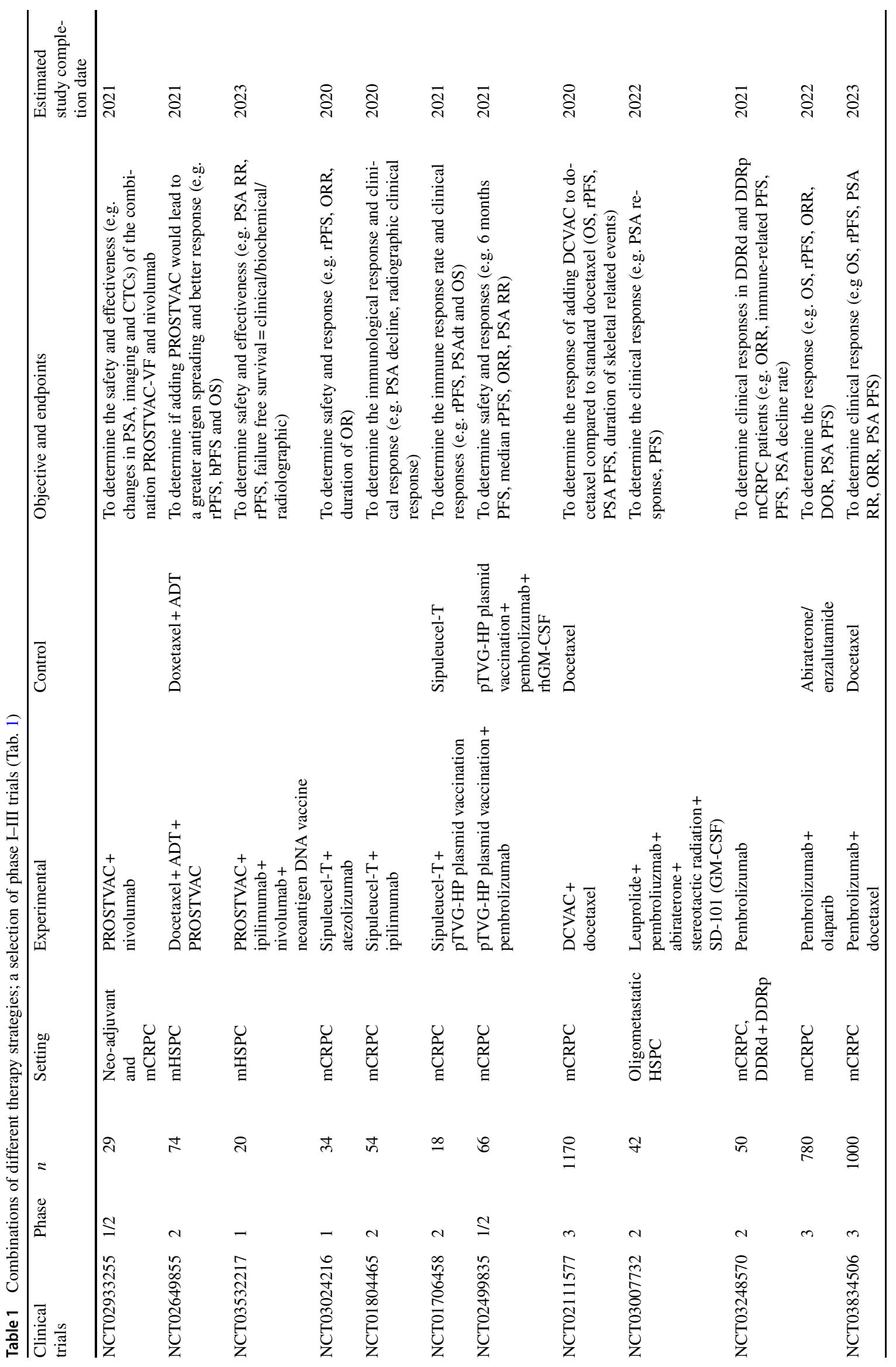




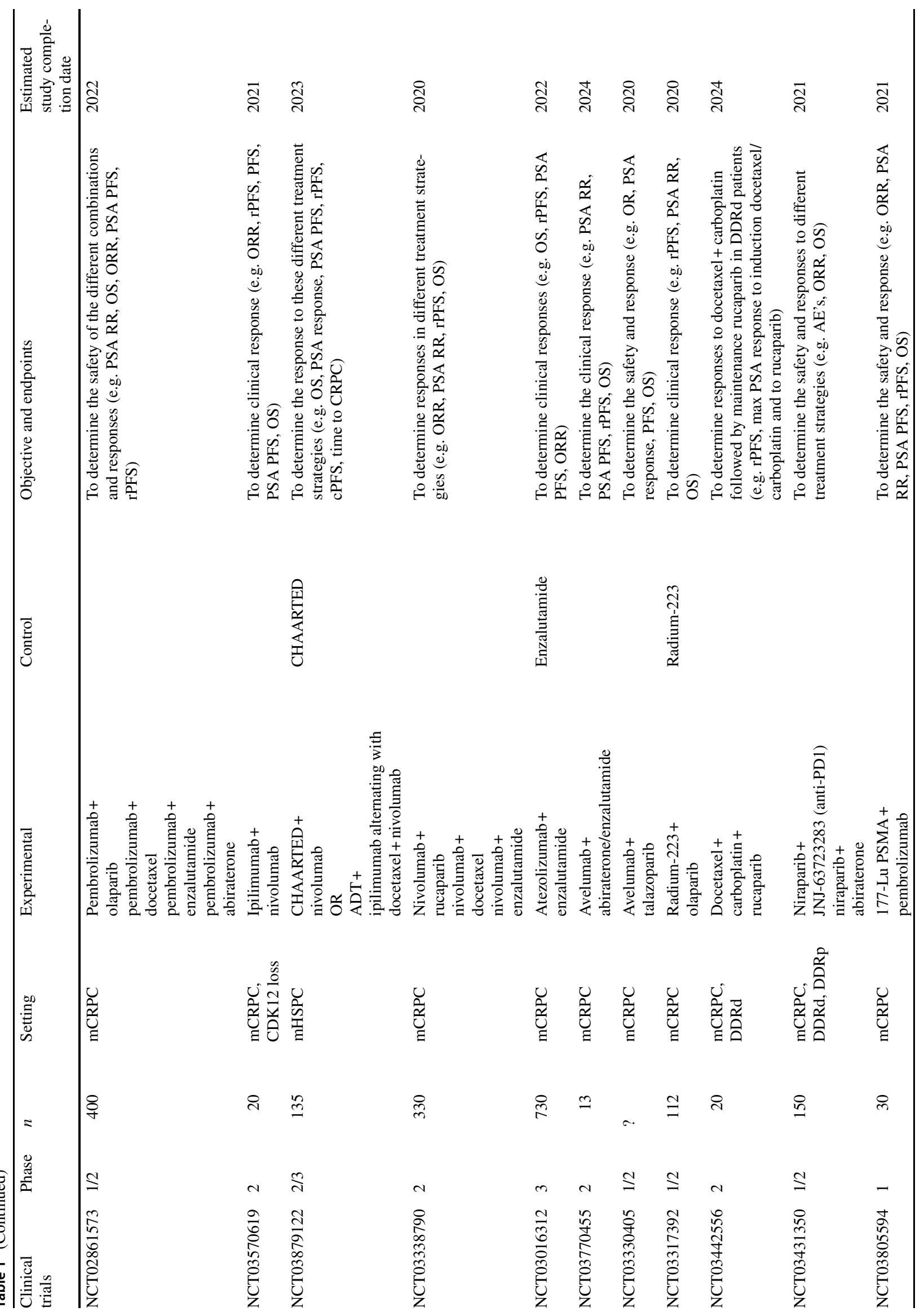




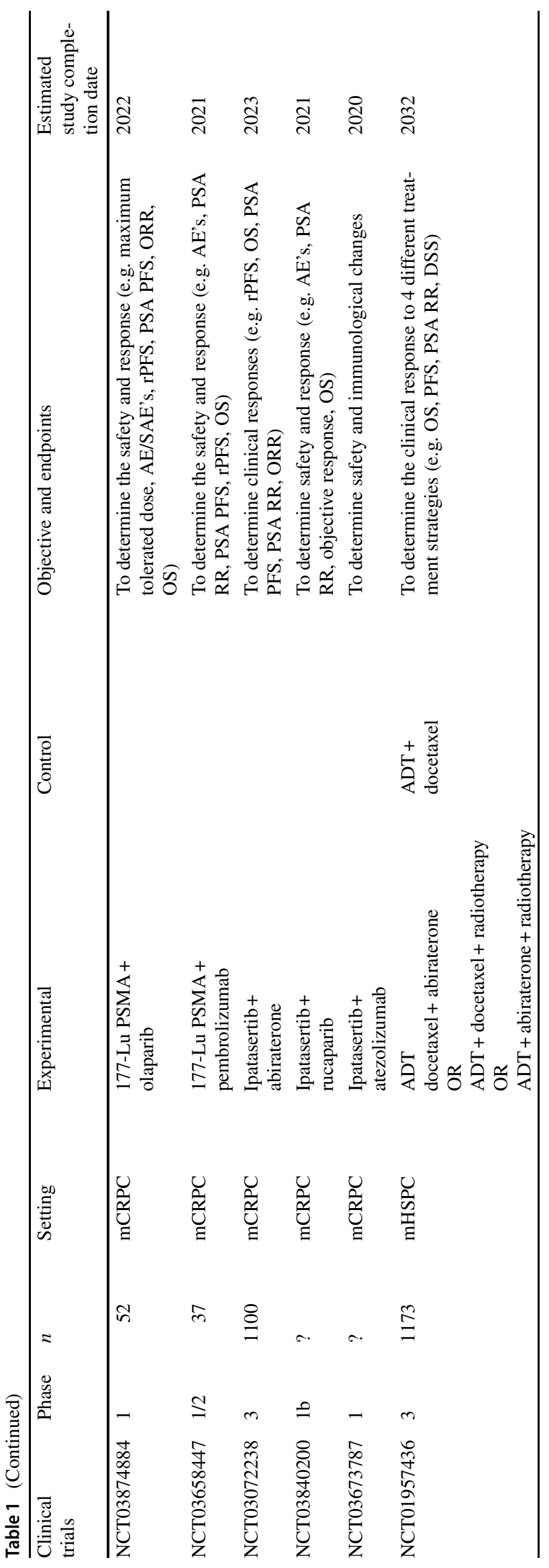

\section{DNA vaccination}

PROSTVAC-VF is a DNA-based vaccine that utilizes PSA as the tumor-specific antigen, and contains two live pox virus-based vectors enclosing transgenes for PSA with 3 co-stimulatory molecules. Due to the positive outcomes of OS (8.5 months longer OS after 3 years follow up) in $\mathrm{mCRPC}$ patients receiving PROSTVAC-VF in a phase II trial in 2010 [16], which was again confirmed in a revision analysis in 2017 [17], a phase III trial was conducted and recently results were published [18]. A total of 1286 patients were included and randomized to be treated with PROSTVAC-VF+ GM-CSF or PROSTVAC-VF+ placebo or placebo + placebo. Surprisingly, no OS benefit was seen between these arms. There were also no differences in secondary endpoints (time to event, HLA-A2 status and tumor response results). These unexpected results are possibly explained by an underpowered OS analysis in the phase II trial (in total 122 patients) [17], biased data collection (OS data collection after data lock up and unblinding), a control arm with worse clinical outcomes than expected (16.6 months vs 20.2 months according to Halabi criteria) and the introduction of new therapies since start of the phase III trial [18]. Based on translational data within this phase III trial, the immunological responses do not translate to the clinical benefit that would be expected, with suggestion that expression of inhibitory checkpoints and other factors dampen the clinical benefit.

Treatment of patients with a DNA-vaccine encoding PAP (pTVG-HP) induced a PAP-specific Th1-biased T cell response $[19,20]$. However, this didn't lead to meaningful PSA decline in cohorts with HSPC or non-metastatic CRPC patients. No randomized studies with monotherapy pTVGHP have yet been conducted in mCRPC patients, however a combination with chemotherapy or immunotherapy will be investigated in currently recruiting trials (Tab. 1).

\section{Checkpoint inhibitors}

The trial results of checkpoint inhibitors in localized and mHSPC are eagerly awaited, as less immunosuppression is seen prior to castration, therefore early initiation of checkpoint blockade may deliver better response rates and/or durable responses. On the other hand, lower neoantigen load in HSPC is seen with on average 1-1.5 mutations $/ \mathrm{Mb}[21,22]$ compared to $2-4.4$ mutations $/ \mathrm{Mb}$ in CRPC [23-25]. In mCRPC multiple trials have been conducted with CTLA-4 and anti-PD1/PD-L1 checkpoint inhibitors, and additional trials are underway that are examining multiple combinatory regimens. 


\section{Anti-PD1 therapy}

Whereas PD-L1 expression is predictive for the response to anti-PD1 therapy in many types of cancer [26, 27], its expression did not associate with objective response or clinical benefit in the largest study to date in prostate cancer [28]. Utilizing different PD-L1 antibodies and cut-off values by different research groups, PD-L1 positivity in primary prostate cancer is estimated between 15-60\% [29-31], and in CRPC between 14-32\% [32, 33].

In the phase Ib KEYNOTE-028 trial 23 patients with PD-L1 positive mCRPC were treated with pembrolizumab. In 4 patients a partial response (PR) occurred, and 8 patients experienced stable disease (SD). The median objective response was 13.5 months, and median OS was 7.9 months [33].

Bishop et al. showed for the first time that timing of checkpoint inhibition may be crucial in prostate cancer, as levels of PD-L1-positive circulating immune cells were altered following resistance to enzalutamide [34]. This led to a small phase II trial by Graff et al. [35], who included 10 chemotherapy-naive patients with mCRPC following enzalutamide resistance, to continue on enzalutamide with addition of pembrolizumab. The remarkable objective responses (60\% non-PD) [35] led to an extended trial and follow-up data that were presented in 2018 showing a biochemical response in $18 \%$ and ORR of $25 \%$ with a median radiographic progression free survival (rPFS) of 10.8 months and median OS of 22.2 months [36].

Outcomes of the previous studies have led to the larger phase II KEYNOTE-199 study, comprising 5 different cohorts. The results of the first three cohorts were presented in 2018 with a recent presentation of longer follow up data at the ASCO GU in 2019 [28]. Although responses to pembrolizumab were durable in most of the patients with a partial or complete response (CR), only a specific subset in the entire cohort, comprising $13 \%$ of unselected patients with mCRPC, seems to take advantage of PD-1 blockage.

The fourth and fifth cohort contain patients who progressed on enzalutamide and continued enzalutamide with the addition of pembrolizumab, to investigate and corroborate the results from Graff et al. [35] whether the combination yields increased responsiveness [28]. The combination of enzalutamide and pembrolizumab will also be investigated in a currently recruiting phase III trial, and will demonstrate the differences in response when pembrolizumab was directly added at the start of enzalutamide compared to enzalutamide alone (NCT03834493). Additionally, two phase III trials are starting to recruit that are testing the combination of pembrolizumab with docetaxel (NCT03834506) and olaparib (NCT02861573), and are discussed further in this review.

\section{Anti-PD-L1 therapy}

Only one study has investigated monotherapy of PD-L1 inhibition in prostate cancer. This phase I study with avelumab included 18 patients with mCRPC who progressed on previous treatment. No responses were observed [37]. In currently active phase $2 / 3$ trials PD-L1 inhibitors are investigated with or without second generation anti-androgen therapy (ADT), or in combination with poly ADP ribose polymerase (PARP) inhibitors (Tab. 1).

\section{Anti-CTLA4 therapy}

Ipilimumab was the first checkpoint inhibitor showing an OS benefit in metastatic melanoma [38]. It is an inhibitor of the CTLA4-B7 pathway, which negatively regulates priming of tumor antigen specific T-cells [1] in lymphoid organs. In earlier phase I/II trials responses were observed in $\mathrm{mCRPC}$ patients receiving ipilimumab [39, 40]. Despite the expectations based on these trials, ipilimumab did improve PFS, but no improvement was observed for OS in two phase III trials [41, 42]. Here, ipilimumab was compared to placebo in chemo-naive [42] and chemotherapy-treated patients [41]. Based on a post hoc multivariate analysis in the study by Kwon et al. [41] OS benefit of ipilimumab was seen only in the patient group with favorable prognostic characteristics. Particularly the presence of visceral metastases was associated with a lack of response to ipilimumab [41].

Both phase III trials [41, 42] suggest that ipilimumab can induce clinical meaningful antitumor responses, however only present in a small subset of patients. Due to a lack of predictive biomarkers associating with ipilimumab responses, monotherapy has limited future in $\mathrm{mCRPC}$, and is mainly of interest in the neo-adjuvant or oligometastatic setting in combination with radiotherapy.

\section{Combination of anti-PD1 and anti-CTLA4 therapy}

A retrospective study by Gao et al. demonstrated an upregulation in PD-L1 immune checkpoint expression on both tumor infiltrating T-cells and tumor cells when treated with ipilimumab [43], suggesting co-administration of PD1/PDL1 checkpoint inhibitors might be able to generate a more effective immune response. This has led to the phase II Checkmate-650 study of which the first results were recently presented [44]. Of the 78 patients who had a minimum follow up of 6 months the objective response rate (ORR) was $26 \%$ vs $10 \%$ in chemo-naive and chemotherapy pretreated patients respectively. In both cohorts ORR was higher in patients with PD-L1 expression $>1 \%$, DNA repair deficiencies or above median tumor mutational burden (TMB) [44]. The toxicity profile of the combo (grade 
3-4 treatment-related AE's 39 and 51\% resp) does not warrant further evaluation in phase III, and additional less toxic regimens are to be studied.

Based on data suggesting that AR-V7 positive prostate cancer harbors more defects in DNA repair genes and has a higher TMB [45] the phase II (STARVE-PC) trial [46] was conducted including 15 patients with AR-V7 positive circulating tumor cells who were treated with the combination of nivolumab and ipilimumab. Preliminary data indicate a PSA response in $13 \%$ and 2 out of 8 patients with measurable disease had an objective response. Interestingly, PFS was significantly longer in DNA repair deficient patients but did not (yet) translate to differences in OS [46].

Other new combinations with ipilimumab and nivolumab are mentioned in Tab. 1.

\section{Targeted therapy}

\section{PARP inhibitors}

In about $20 \%$ of the patients with mCRPC DNA repair deficiencies, mutations or deletions in DNA repair genes such as BRCA1/2, ATM CHEK1/2, RAD51B, CDK12 and the Fanconi anemia genes, can be found [23, 24]. When a single-strand break occurs in DNA, PARP 1 and 2 binds to this break and by generating PAR polymers (PARylation) on itself and target proteins, PARP is able to recruit repair proteins that have roles in different aspects of DNA damage repair [47, 48]. PARP-1 is also able to repair doublestrand breaks in DNA. Cumulative PARylation ultimately leads to dissociation of PARP from the DNA. PARP inhibition results in accumulation of unrepaired DNA breaks and trapping of PARP on DNA. Reparation of these breaks requires DNA repair genes from the homologous repair (HR) pathway. However, if these DNA repair genes are mutated and a PARP inhibitor is administered, accumulation of both single and double strand breaks occurs, eventually leading to apoptosis of the cell.

While no studies have investigated PARP inhibitors in mHSPC, several studies have been published in patients with mCRPC targeting those with DNA damage response deficiency (DDRd) with PARP inhibitors.

In a phase II trial the PARP inhibitor olaparib was investigated in 49 patients. DDRd patients experienced a significantly higher ORR (88\% vs 6\%) and a longer median PFS (9.8 vs 2.7 months) and OS (13.8 vs 7.5 months) [49]. This study has led to the large multicenter phase III ProFOUND trial in which patients were randomized to either olaparib or either abiraterone or enzalutamide. The first results of this study will be expected this year (NCT02987543). A recently published retrospective study demonstrated the responses adjusted to the different DNA repair deficiencies
[50]. Interestingly, while 4 out of 6 patients with an ATM mutation had a response to olaparib in the study by Mateo et al. [49], none of the 6 patients in this retrospective study achieved a response [50]. For BRCA 1/2 mutations response rates were promising (90 and 76\%) in both studies[49, 50]. In the ongoing phase II trial with niraparib first preliminary data also suggest higher response rates in patients with BRCA1/2 versus other DDR deficiencies (NCT02854436). The larger phase III trials (NCT02987543, NCT02975934) may give us more insights in the response to PARP inhibitors in patients with different DNA repair deficiencies.

Other PAPR inhibitors, such as talazoparib, niraparib and rucaparib, are currently also under investigation in patients with mCRPC. In mHSPC one small phase II trial is conducted to investigate the response of rucaparib in DDR defiecient patients (NCT03413995).

Polkinghorn et al. was able to demonstrate that AR signaling increases the expression of DNA repair genes from the HR pathway [51]. As discussed earlier HR is necessary to repair double-strand breaks in DNA. It was hypothesized that androgen-deprivation therapy (ADT) would decrease activity of $\mathrm{HR}$, thereby inhibiting repair of double-strand breaks, which would lead to an increase of PARP activity. This was indeed proved by Asim et al. [52] leading to the hypothesis that the combination of ADT and a PARP inhibitor would be more effective than ADT alone. This implicates that PARP inhibitors may also be effective in DDR proficient patients [52]. A phase II trial randomizing patients to abiraterone + olaparib versus abiraterone + placebo [53], although not powered to test differences between DDR proficient and deficient patients, hinted that the 5.6 months rPFS benefit of the combo was independent of DDR status. This suggests that there is benefit from olaparib in DDR proficient patients, but probably only when combined with second-generation androgen-signaling inhibition [49, 53]. A larger double-blind placebo-controlled phase III trial (NCT03732820) just started including patients to investigate whether adding olaparib to abiraterone indeed provides better outcomes than monotherapy abiraterone in first-line mCRPC patients. Phase III trials are also investigating the combination of abiraterone with or without niraparib (NCT03748641) and enzalutamide with or without talazoparib (NCT03395197) in mCRPC patients.

\section{Nuclear medicine}

As prostate specific membrane antigen (PSMA) is overexpressed in prostate adenocarcinoma, and even more strongly enhanced following initiation of ADT or AR signaling inhibitors, several groups investigated the effect of targeting PSMA utilizing radionuclide-labeled ligands. PSMA is labelled to either alpha- or beta-emitting radioligands. Alpha- 
emitters (e.g. 225-Actinium, 227-Thorium) are highly energetic particles translating into substantial tissue damage around the particle, while beta-emitters (e.g. 177-Lutetium) have a much lower energy transmission but higher tissue penetration. Both types of PSMA ligand therapies have been investigated in $\mathrm{mCRPC}$ and will be discussed below.

\section{7-Lu PSMA ligand therapy}

Several single-arm studies, performed between 2016 and 2018 in Germany [54-58] and recently in the Netherlands [59] and Australia [60], have shown extraordinary biochemical response rates in advanced and often end-stage mCRPC patients.

With a PSA response of $45-60 \%$ and a longer rPFS and OS 177-Lu PSMA therapy seems to be a promising treatment in patients with mCRPC, which led to a currently recruiting phase 3 trial with heavily pretreated mCRPC patients randomized between 177-Lu PSMA therapy and best supportive care/standard of care (NCT03511664). The question is whether 177-Lu PMSA therapy improves outcome compared to current available therapies. A phase II trial will also evaluate differences in overall survival in patients with mCRPC randomized between either cabazitaxel or 177-Lu PSMA therapy (NCT03392428).

There are no results of 177-Lu PSMA therapy in prospective studies with newly diagnosed HSPC or early CRPC patients. To evaluate feasibility of Lu177-PSMA therapy in low volume mHSPC patients, a prospective trial is now currently being conducted at the Radboudumc (NCT03828838).

\section{5-Ac PSMA ligand therapy}

At present, only two unique cohorts [61, 62] have been treated with 225-Ac-PSMA therapy and in retrospect analyzed. Both studies showed remarkable PSA response rates ranging from $63 \%$ in heavily pretreated mCRPC patients [61] to $82 \%$ in hormone sensitive and first-line CRPC patients [62]. Grade 3-4 xerostomia was common and $13 \%$ of patients discontinued therapy due to this toxicity despite many of these were responding [61]. Although results are promising in both $\mathrm{mHSPC}$ and $\mathrm{mCRPC}$ cancer, larger prospective trials with 225-Ac PSMA therapy are needed for increased understanding on issues regarding safety and toxicity, response rate and duration of response, in both disease states.

\section{The genomic landscape of prostate cancer}

During the last decade a comprehensive insight was obtained regarding the genomic landscape of primary and metastatic prostate cancer through results from multiple large next generation sequencing (NGS) studies [22-25, 63-65]. Results show both commonalities as heterogeneity between patients, regarding genetic alterations in key signaling pathways such as AR signaling, DNA repair and chromatin remodeling, PI3K/Akt/mTOR, MAPK and Wnt.

In the era of precision medicine, molecular profiling is becoming paramount for the identification of patients that may benefit from specific targeted therapies, for example PARP- and PI3K-inhibitors. It could also guide us in selecting different treatment regimens than the currently registered options, for instance preferring taxane-based chemotherapy in case of presence of AR gain or AR splice variant 7 , which appear to be associated with resistance to AR inhibitors [66, 67].

Approximately $35-60 \%$ of patients with metastatic prostate cancer [24, 65] show inactivation of PTEN, an important tumor suppressor and guardian of the genome, through loss of function mutations or through (focal) loss. Inactivation of PTEN leads to hyperactivation of the PI3KAkt-mTOR pathway [24]. This is of importance, as there is clinically relevant cross-talk between AR signaling and the PI3K-Akt-mTOR pathway; when targeting AR signaling, for example by enzalutamide or abiraterone, activation of the PI3K-Akt-mTOR overrides the inhibitory effects of these agents through downstream activation of androgen responsive genes [68]. Inhibition of the PI3K-AktmTOR pathway therefore has received remarkable interest as novel target in prostate cancer. Early phase clinical trials with monotherapy PI3K or mTOR inhibitors, however, did not report meaningful clinical responses in patients with mCRPC [69, 70]. Recently a phase II trial was published demonstrating a prolonged rPFS and trend towards PSA PFS and OS when combining an Akt-inhibitor with abiraterone, which was even more evident in patients with PTEN loss [71]. Clinical responses of this Akt-inhibitor in combination with abiraterone are currently evaluated in a phase III trial (NCT03072238).

Results from a whole genome sequencing study from a Dutch patient cohort, comprising 197 mCRPC patients from the CPCT-02 study (NCT01855477), were recently presented at ASCO and ESMO. These findings support use of NGS for precision medicine, as the authors were able to demonstrate different relevant biological subtypes of prostate cancer, based on unsupervised clustering of genetic aberrations. Clinically relevant genotypes include clusters with microsatellite instability (MSI), homologous recombinant deficiency, biallelic loss of CDK12 and a group enriched for chromothripsis events [23].

Mismatch repair (MMR) deficiency leading to MSI yields a high tumor mutational burden with corresponding high neoantigen load. MSI and/or MMR deficiency are therefore an ideal tumor-agnostic and predictive biomarker 
for checkpoint immunotherapy. The prevalence of MSI in mCRPC is between 3-7\% [23, 24, 72-75]. Recently a small retrospective study ( $n=11 \mathrm{MSI} / \mathrm{MMR}$ deficient patients) presented by Abida et al. showed impressive and durable responses to anti-PD1 therapy; $54.5 \%$ had a PSA decline of $>50 \%$ of whom $67.7 \%$ had also a radiologic response. [74]. The Drug Rediscovery Program (DRUP-study) in the Netherlands has used this tumor-agnostic biomarker as selection criterium for a checkpoint inhibitor cohort, and was able to confirm the impressive response rates published before. These data support the use of routine MSI testing and/or next-generation sequencing in all patients with metastatic prostate cancer.

Biallelic inactivation of CDK12, a key player in the DNA repair pathway, results in a distinct genetic fingerprint, comprising focal tandem duplications and gene fusions across the genome, and is recently identified as a novel molecular subtype by $\mathrm{Wu}$ et al. [76]. CDK12 inactivation is present in about $7 \%$ of mCRPC patients $[23,76]$, and this tumor subtype appears to be very immunogenic due to a high neoantigen burden resulting from the genetic rearrangements and focal amplifications. This is accompanied by higher $\mathrm{T}$ cell infiltration compared to wildtype patients [76], which led to the study by $\mathrm{Wu}$ et al. evaluating whether these patients were good responders to immune checkpoint inhibition[76]. In retrospect, 2 out of 4 CDK12loss mCRPC patients treated with anti-PD1 therapy had an exceptional response which led to a phase 2 trial recruiting patients to investigate whether ipilimumab in combination with nivolumab leads to even better responses in this particular group of patients (NCT03570619).

\section{Combinations of different strategies and pre- selected prostate cancer subtypes: future perspectives}

\section{Presorting based on molecular profiling}

As discussed above, several NGS studies have demonstrated a presence of various different targetable genetic aberrations in prostate cancer. MMR deficiency/MSI and DDR deficiency have both led to several clinical trials with new targeted therapies, some demonstrating impressive results regarding response rate. In DDR deficient patients, besides PARP inhibitors and platinum chemotherapy, additional options could also provide better outcomes. For example, checkpoint inhibitors show higher responses in DDR deficient patients compared to DDR proficient patients due to a higher mutational burden witnessed in DDR deficient patients, indicating more neoantigens are available to be presented to our immune system [23, 24, 76]. Three currently recruiting studies (NCT03330405, NCT03431350,
NCT03248570) will give us more insights. Another example is the combination of radioligand therapy and PARP inhibitors (NCT03874884, NCT03317392) which is based on the finding that patients harboring DDR deficiencies are having better outcomes following radium-223 [77] and probably also to 177-Lu PSMA therapy [78].

Genetic profiling and stratification of other genetic aberrations, including CDK12 and alterations in the PI3K/Akt/ mTOR pathway, are also future targets for novel drugs and regimens, and are currently under investigation (NCT03072238, NCT03570619).

\section{Combination therapies}

The current guidelines provide us with various options for sequential treatment of drugs in monotherapy, however we foresee the future in multi-drug combinations.

For immunotherapy, interfering simultaneously in different steps of the cancer-immunity cycle likely will boost responsiveness and long-term outcome. For example, the combination of pTVG-HP vaccines followed by anti-PD1 therapy increased immunological and clinical response [79], which led to a still ongoing larger randomized phase I/II trial (NCT02499835).

Since many vaccines are able to induce tumor antigenspecific T-cell responses, combinatory treatment might benefit from this prime-boost strategy in the future. For example, a currently recruiting trial is investigating the effects of combining PROSTVAC with a tumor antigen specific DNA vaccination and ipilimumab/nivolumab in patients with mHSPC (NCT03532217).

The release of cancer cell antigens, that may result following treatment with chemotherapy and targeted agents, hypothetically activate an immune response by the priming and activation of $\mathrm{T}$ cells. If checkpoints inhibiting an immune response against cancer cells can be blocked, synergy of these agents is expected. Combinations of chemotherapy and targeted therapy (e.g. PARP inhibitors) with anti-PD1 or anti-CTLA4 checkpoint inhibitors are currently being investigation in several phase II/III trials in mHSPC and mCRPC (Tab. 1). For example, a randomized multi-arm trial started recently to recruit patients, and is investigating whether the addition of nivolumab, or nivolumab in combination with ipilimumab, to docetaxel (CHAARTED regimen) would improve OS in patients with mHSPC with regard to docetaxel alone (NCT03879122). Another trial is being conducted to evaluate the addition of neo-adjuvant ipilimumab and degarelix in low volume mHSPC and interim results demonstrated in 6 of 7 patients ultra-low PSA levels during follow up after radical prostatectomy, and long-term follow-up is eagerly awaited (NCT02020070). The PEACE-1 randomized phase III trial (NCT01957436) is investigating what treat- 
ment strategy would be best in mHSPC; ADT + docetaxel, $\mathrm{ADT}+$ docetaxel + abiraterone, ADT + docetaxel + local radiotherapy, $\quad \mathrm{ADT}+$ docetaxel+ local radiotherapy + abiraterone with regard to PFS and OS.

The combination of docetaxel, second generation androgen signaling inhibition and/or PARP inhibitors with checkpoint inhibitors are evaluated in many different phase II/III trials (Tab. 1) in CRPC, and the first results of combinational strategies are expected next year (e.g. NCT03338790, NCT03330405).

In conclusion, an extensive number of combinatory treatment strategies are being studied in metastatic prostate cancer, and even though some of these regimens will prove successful in improving outcome, an acceptable toxicity profile still remains paramount in this elderly population and palliative setting.

Acknowledgements We would like to thank Martijn den Brok, $\mathrm{PhD}$, Department of Medical oncology Radboud University Medical Center Nijmegen, and Igle Jan de Jong, MD, PhD, Department of Urology University Medical Center Groningen, for their critical review on this paper.

Conflict of interest M. Smits declares that she has no competing interests, W. Gerritsen received speaker fees from Astellas, Bayer, Merck Sharp \& Dohme (MSD) and European Society for Medical Oncology, participated in advisory boards of Amgen, Bayer, Bristol-Myers Squibb, Curevac, Dendreon, IQVIA, Janssen-Cilag, Merck (MSD), Morphosys and Sanofi, and received research grants from Astellas, Amgen, Bayer, Janssen-Cilaq and Sanofi. N. Mehra played an advisory role (both institutional as personal) for Roche, MSD, Bayer, Astellas and Janssen, he received research support (institutional) from Astellas, Janssen, Pfizer, Roche and Sanofi, Genzyme and travel support from Astellas, MSD.

Open Access This article is distributed under the terms of the Creative Commons Attribution 4.0 International License (http:// creativecommons.org/licenses/by/4.0/), which permits unrestricted use, distribution, and reproduction in any medium, provided you give appropriate credit to the original author(s) and the source, provide a link to the Creative Commons license, and indicate if changes were made.

\section{References}

1. Chen DS, Mellman I. Oncology meets immunology: the cancerimmunity cycle. Immunity. 2013;39(1):1-10.

2. Miller AM, Lundberg K, Ozenci V, Banham AH, Hellstrom M, Egevad L, et al. CD4+CD25high $\mathrm{T}$ cells are enriched in the tumor and peripheral blood of prostate cancer patients. J Immunol. 2006;177(10):7398-405.

3. Kiniwa Y, Miyahara Y, Wang HY, Peng W, Peng G, Wheeler TM, et al. CD8+ Foxp3+ regulatory T cells mediate immunosuppression in prostate cancer. Clin Cancer Res. 2007;13(23):6947-58.

4. Sallusto F, Lanzavecchia A. Efficient presentation of soluble antigen by cultured human dendritic cells is maintained by granulocyte/macrophage colony-stimulating factor plus interleukin 4 and downregulated by tumor necrosis factor alpha. J Exp Med. 1994;179(4):1109-18.

5. Tel J, Aarntzen EH, Baba T, Schreibelt G, Schulte BM, BenitezRibas D, et al. Natural human plasmacytoid dendritic cells induce antigen-specific T-cell responses in melanoma patients. Cancer Res. 2013;73(3):1063-75.

6. Schreibelt G, Bol KF, Westdorp H, Wimmers F, Aarntzen EH, Duiveman-de Boer T, et al. Effective clinical responses in metastatic melanoma patients after vaccination with primary Myeloid dendritic cells. Clin Cancer Res. 2016;22(9):2155-66.

7. Waeckerle-Men Y, Uetz-von Allmen E, Fopp M, von Moos R, Bohme C, Schmid HP, et al. Dendritic cell-based multi-epitope immunotherapy of hormone-refractory prostate carcinoma. Cancer Immunol Immunother. 2006;55(12):1524-33.

8. Fuessel S, Meye A, Schmitz M, Zastrow S, Linne C, Richter K, et al. Vaccination of hormone-refractory prostate cancer patients with peptide cocktail-loaded dendritic cells: results of a phase I clinical trial. Prostate. 2006;66(8):811-21.

9. Reyes D, Salazar L, Espinoza E, Pereda C, Castellon E, Valdevenito $\mathrm{R}$, et al. Tumour cell lysate-loaded dendritic cell vaccine induces biochemical and memory immune response in castration-resistant prostate cancer patients. Br J Cancer. 2013;109(6):1488-97.

10. Kodumudi KN, Woan K, Gilvary DL, Sahakian E, Wei S, Djeu JY. A novel chemoimmunomodulating property of docetaxel: suppression of myeloid-derived suppressor cells in tumor bearers. Clin Cancer Res. 2010;16(18):4583-94.

11. Kongsted P, Borch TH, Ellebaek E, Iversen TZ, Andersen R, Met O, et al. Dendritic cell vaccination in combination with docetaxel for patients with metastatic castration-resistant prostate cancer: a randomized phase II study. Cytotherapy. 2017;19(4):500-13.

12. Handy CE, Antonarakis ES. Sipuleucel-T for the treatment of prostate cancer: novel insights and future directions. Future Oncol. 2018;14(10):907-17.

13. Small EJ, Schellhammer PF, Higano CS, Redfern CH, Nemunaitis JJ, Valone FH, et al. Placebo-controlled phase III trial of immunologic therapy with sipuleucel-T (APC8015) in patients with metastatic, asymptomatic hormone refractory prostate cancer. J Clin Oncol. 2006;24(19):3089-94.

14. Higano CS, Schellhammer PF, Small EJ, Burch PA, Nemunaitis $\mathrm{J}$, Yuh $\mathrm{L}$, et al. Integrated data from 2 randomized, double-blind, placebo-controlled, phase 3 trials of active cellular immunotherapy with sipuleucel- $\mathrm{T}$ in advanced prostate cancer. Cancer. 2009;115(16):3670-9.

15. Kantoff PW, Higano CS, Shore ND, Berger ER, Small EJ, Penson DF, et al. Sipuleucel-T immunotherapy for castration-resistant prostate cancer. N Engl J Med. 2010;363(5):411-22.

16. Kantoff PW, Schuetz TJ, Blumenstein BA, Glode LM, Bilhartz DL, Wyand $\mathrm{M}$, et al. Overall survival analysis of a phase II randomized controlled trial of a Poxviral-based PSA-targeted immunotherapy in metastatic castration-resistant prostate cancer. J Clin Oncol. 2010;28(7):1099-105.

17. Kantoff PW, Gulley JL, Pico-Navarro C. Revised overall survival analysis of a phase ii, randomized, double-blind, controlled study of PROSTVAC in men with metastatic castration-resistant prostate cancer. J Clin Oncol. 2017;35(1):124-5.

18. Gulley JL, Borre M, Vogelzang NJ, Ng S, Agarwal N, Parker CC, et al. Phase III trial of PROSTVAC in asymptomatic or minimally symptomatic metastatic castration-resistant prostate cancer. J Clin Oncol. 2019. https://doi.org/10.1200/JCO.18.02031.

19. McNeel DG, Becker JT, Eickhoff JC, Johnson LE, Bradley E, Pohlkamp I, et al. Real-time immune monitoring to guide plasmid DNA vaccination schedule targeting prostatic acid phosphatase in patients with castration-resistant prostate cancer. Clin Cancer Res. 2014;20(14):3692-704.

20. McNeel DG, Dunphy EJ, Davies JG, Frye TP, Johnson LE, Staab MJ, et al. Safety and immunological efficacy of a DNA vaccine encoding prostatic acid phosphatase in patients with stage D0 prostate cancer. J Clin Oncol. 2009;27(25):4047-54.

21. Cancer Genome Research AN. The molecular taxonomy of primary prostate cancer. Cell. 2015;163(4):1011-25. 
22. Barbieri CE, Baca SC, Lawrence MS, Demichelis F, Blattner M, Theurillat JP, et al. Exome sequencing identifies recurrent SPOP, FOXA1 and MED12 mutations in prostate cancer. Nat Genet. 2012;44(6):685-9.

23. van Dessel LF, van Riet J, Smits M, Zhu Y, Hamberg P, van der Heijden MS, et al. The genomic landscape of metastatic castrationresistant prostate cancers using whole genome sequencing reveals multiple distinct genotypes with potential clinical impact. 2019. https://doi.org/10.1101/546051. Accessed 11 Feb 2019.

24. Robinson D, van Allen EM, Wu YM, Schultz N, Lonigro RJ, Mosquera JM, et al. Integrative clinical genomics of advanced prostate cancer. Cell. 2015;162(2):454.

25. Grasso CS, Wu YM, Robinson DR, Cao X, Dhanasekaran SM, Khan AP, et al. The mutational landscape of lethal castration-resistant prostate cancer. Nature. 2012;487(7406):239-43.

26. Topalian SL, Drake CG, Pardoll DM. Targeting the PD-1/B7H1(PD-L1) pathway to activate anti-tumor immunity. Curr Opin Immunol. 2012;24(2):207-12.

27. Herbst RS, Baas P, Kim DW, Felip E, Perez-Gracia JL, Han JY, et al. Pembrolizumab versus docetaxel for previously treated, PD-L1positive, advanced non-small-cell lung cancer (KEYNOTE-010): a randomised controlled trial. Lancet. 2016;387(10027):1540-50.

28. Antonarakis ES, Goh JC, Gross-Goupil M, Vaishampayan UN, Piulats JM, Wit RD, et al. Pembrolizumab for metastatic castration-resistant prostate cancer (mCRPC) previously treated with docetaxel: Updated analysis of KEYNOTE-199. J Clin Oncol. 2019;37(7 suppl):216.

29. Gevensleben H, Dietrich D, Golletz C, Steiner S, Jung M, Thiesler T, et al. The Immune checkpoint regulator PD-L1 is highly expressed in aggressive primary prostate cancer. Clin Cancer Res. 2016;22(8):1969-77.

30. Vidotto T, Saggioro FP, Jamaspishvili T, Chesca DL, Picanco de Albuquerque CG, Reis RB, et al. PTEN-deficient prostate cancer is associated with an immunosuppressive tumor microenvironment mediated by increased expression of IDO1 and infiltrating FoxP3+ T regulatory cells. Prostate. 2019;79(9):969-79.

31. Martin AM, Nirschl TR, Nirschl CJ, Francica BJ, Kochel CM, van Bokhoven A, et al. Paucity of PD-L1 expression in prostate cancer: innate and adaptive immune resistance. Prostate Cancer Prostatic Dis. 2015;18(4):325-32.

32. Haffner MC, Guner G, Taheri D, Netto GJ, Palsgrove DN, Zheng Q, et al. Comprehensive evaluation of programmed death-ligand 1 expression in primary and metastatic prostate cancer. Am J Pathol. 2018;188(6):1478-85.

33. Hansen AR, Massard C, Ott PA, Haas NB, Lopez JS, Ejadi S, et al. Pembrolizumab for advanced prostate adenocarcinoma: findings of the KEYNOTE-028 study. Ann Oncol. 2018;29(8):1807-13.

34. Bishop JL, Sio A, Angeles A, Roberts ME, Azad AA, Chi KN, et al. PD-L1 is highly expressed in enzalutamide resistant prostate cancer. Oncotarget. 2015;6(1):234-42.

35. Graff JN, Alumkal JJ, Drake CG, Thomas GV, Redmond WL, Farhad M, et al. Early evidence of anti-PD-1 activity in enzalutamide-resistant prostate cancer. Oncotarget. 2016;7(33):52810-7.

36. Graff JN, Alumkal JJ, Thompson RF, Moran A, Thomas GV, Wood MA, et al. Pembrolizumab (Pembro) plus enzalutamide (Enz) in metastatic castration resistant prostate cancer (mCRPC): Extended follow up. J Clin Oncol. 2018;36(15 suppl):5047.

37. Fakhrejahani F, Madan RA, Dahut WL, Karzai F, Cordes LM, Schlom J, et al. Avelumab in metastatic castration-resistant prostate cancer (mCRPC). J Clin Oncol. 2017;35(6):159. suppl 20 februari.

38. Hodi FS, O'Day SJ, McDermott DF, Weber RW, Sosman JA, Haanen JB, et al. Improved survival with ipilimumab in patients with metastatic melanoma. N Engl J Med. 2010;363(8):711-23.

39. Small EJ, Tchekmedyian NS, Rini BI, Fong L, Lowy I, Allison JP. A pilot trial of CTLA-4 blockade with human anti-CTLA-4 in pa- tients with hormone-refractory prostate cancer. Clin Cancer Res. 2007;13(6):1810-5.

40. Slovin SF, Higano CS, Hamid O, Tejwani S, Harzstark A, Alumkal JJ, et al. Ipilimumab alone or in combination with radiotherapy in metastatic castration-resistant prostate cancer: results from an openlabel, multicenter phase I/II study. Ann Oncol. 2013;24(7):1813-21.

41. Kwon ED, Drake CG, Scher HI, Fizazi K, Bossi A, van den Eertwegh AJ, et al. Ipilimumab versus placebo after radiotherapy in patients with metastatic castration-resistant prostate cancer that had progressed after docetaxel chemotherapy (CA184-043): a multicentre, randomised, double-blind, phase 3 trial. Lancet Oncol. 2014;15(7):700-12.

42. Beer TM, Kwon ED, Drake CG, Fizazi K, Logothetis C, Gravis G, et al. Randomized, double-blind, phase iii trial of ipilimumab versus placebo in asymptomatic or minimally symptomatic patients with metastatic chemotherapy-naive castration-resistant prostate cancer. J Clin Oncol. 2017;35(1):40-7.

43. Gao J, Ward JF, Pettaway CA, Shi LZ, Subudhi SK, Vence LM, et al. VISTA is an inhibitory immune checkpoint that is increased after ipilimumab therapy in patients with prostate cancer. Nat Med. 2017;23(5):551-5.

44. Sharma P, Pachynski RK, Narayan V, Flechon A, Gravis G, Galsky MD, et al. Initial results from a phase II study of nivolumab (NIVO) plus ipilimumab (IPI) for the treatment of metastatic castration-resistant prostate cancer (mCRPC; CheckMate 650). J Clin Oncol. 2019;37(7):142.

45. Joshi H, Pinski JK. Association of ARV7 expression with molecular and clinical characteristics in prostate cancer. J Clin Oncol. 2016;34(2):109.

46. Boudadi K, Suzman DL, Anagnostou V, Fu W, Luber B, Wang H, et al. Ipilimumab plus nivolumab and DNA-repair defects in ARV7-expressing metastatic prostate cancer. Oncotarget. 2018;9(47): 28561-71.

47. Pommier Y, O’Connor MJ, de Bono J. Laying a trap to kill cancer cells: PARP inhibitors and their mechanisms of action. Sci Transl Med. 2016;8(362): 17.

48. Chaudhuri RA, Nussenzweig A. The multifaceted roles of PARP1 in DNA repair and chromatin remodelling. Nat Rev Mol Cell Biol. 2017;18(10):610-21.

49. Mateo J, Carreira S, Sandhu S, Miranda S, Mossop H, PerezLopez R, et al. DNA-repair defects and olaparib in metastatic prostate cancer. N Engl J Med. 2015;373(18):1697-708.

50. Marshall CH, Sokolova AO, McNatty AL, Cheng HH, Eisenberger MA, Bryce $\mathrm{AH}$, et al. differential response to olaparib treatment among men with metastatic castration-resistant prostate cancer harboring BRCA1 or BRCA2 versus ATM mutations. Eur Urol. 2019. https://doi.org/10.1016/j.eururo.2019.02.002.

51. Polkinghorn WR, Parker JS, Lee MX, Kass EM, Spratt DE, Iaquinta PJ, et al. Androgen receptor signaling regulates DNA repair in prostate cancers. Cancer Discov. 2013;3(11):1245-53.

52. Asim M, Tarish F, Zecchini HI, Sanjiv K, Gelali E, Massie CE, et al. Synthetic lethality between androgen receptor signalling and the PARP pathway in prostate cancer. Nat Commun. 2017;8(1):374.

53. Clarke N, Wiechno P, Alekseev B, Sala N, Jones R, Kocak I, et al. Olaparib combined with abiraterone in patients with metastatic castration-resistant prostate cancer: a randomised, double-blind, placebo-controlled, phase 2 trial. Lancet Oncol. 2018;19(7):975-86.

54. Rahbar K, Ahmadzadehfar H, Kratochwil C, Haberkorn U, Schafers M, Essler M, et al. German multicenter study investigating 177Lu-PSMA-617 radioligand therapy in advanced prostate cancer patients. J Nucl Med. 2017;58(1):85-90.

55. Heck MM, Tauber R, Schwaiger S, Retz M, D'Alessandria C, Maurer $\mathrm{T}$, et al. Treatment outcome, toxicity, and predictive factors for radioligand therapy with (177)Lu-PSMA-I\&T in metastatic castration-resistant prostate cancer. Eur Urol. 2019;75(6):920-6. 
56. Ahmadzadehfar H, Wegen S, Yordanova A, Fimmers R, Kurpig S, Eppard E, et al. Overall survival and response pattern of castrationresistant metastatic prostate cancer to multiple cycles of radioligand therapy using [(177)Lu]Lu-PSMA-617. Eur J Nucl Med Mol Imaging. 2017;44(9):1448-54.

57. Hofman MS, Violet J, Hicks RJ, Ferdinandus J, Thang SP, Akhurst T, et al. [(177)Lu]-PSMA-617 radionuclide treatment in patients with metastatic castration-resistant prostate cancer (LuPSMA trial): a single-centre, single-arm, phase 2 study. Lancet Oncol. 2018;19(6):825-33.

58. Kratochwil C, Giesel FL, Stefanova M, Benesova M, Bronzel M, Afshar-Oromieh A, et al. PSMA-targeted radionuclide therapy of metastatic castration-resistant prostate cancer with $177 \mathrm{Lu}$-Labeled PSMA-617. J Nucl Med. 2016;57(8):1170-6.

59. van Kalmthout L, Braat A, Lam M, van Leeuwaarde R, Krijger G, Ververs T, et al. First experience with 177Lu-PSMA-617 therapy for advanced prostate cancer in the Netherlands. Clin Nucl Med. 2019;44(6):446-51.

60. McBean R, O'Kane B, Parsons R, Wong D. Lu177-PSMA therapy for men with advanced prostate cancer: Initial 18 months experience at a single Australian tertiary institution. J Med Imaging Radiat Oncol. 2019. https://doi.org/10.1111/1754-9485.12891.

61. Kratochwil C, Bruchertseifer F, Rathke H, Hohenfellner M, Giesel FL, Haberkorn U, et al. Targeted alpha-therapy of metastatic castration-resistant prostate cancer with (225)Ac-PSMA-617: swimmer-plot analysis suggests efficacy regarding duration of tumor control. J Nucl Med. 2018;59(5):795-802.

62. Sathekge M, Bruchertseifer F, Knoesen O, Reyneke F, Lawal I, Lengana T, et al. (225)Ac-PSMA-617 in chemotherapy-naive patients with advanced prostate cancer: a pilot study. Eur J Nucl Med Mol Imaging. 2019;46(1):129-38.

63. Viswanathan SR, Ha G, Hoff AM, Wala JA, Carrot-Zhang J, Whelan $\mathrm{CW}$, et al. Structural alterations driving castration-resistant prostate cancer revealed by linked-read genome sequencing. Cell. 2018;174(2):433-47 e19.

64. Armenia J, Wankowicz SAM, Liu D, Gao J, Kundra R, Reznik E, et al. The long tail of oncogenic drivers in prostate cancer. Nat Genet. 2018;50(5):645-51.

65. Quigley DA, Dang HX, Zhao SG, Lloyd P, Aggarwal R, Alumkal JJ, et al. Genomic hallmarks and structural variation in metastatic prostate cancer. Cell. 2018;175(3):889.

66. Romanel A, Gasi Tandefelt D, Conteduca V, Jayaram A, Casiraghi N, Wetterskog D, et al. Plasma AR and abiraterone-resistant prostate cancer. Sci Transl Med. 2015;7(312):10.

67. Armstrong AJ, Halabi S, Luo J, Nanus DM, Giannakakou P, Szmulewitz RZ, et al. Prospective multicenter validation of androgen receptor splice variant 7 and hormone therapy resistance in highrisk castration-resistant prostate cancer: The PROPHECY study. J Clin Oncol. 2019;37(13):1120-9.

68. Carver BS, Chapinski C, Wongvipat J, Hieronymus H, Chen Y, Chandarlapaty S, et al. Reciprocal feedback regulation of PI3K and androgen receptor signaling in PTEN-deficient prostate cancer. Cancer Cell. 2011;19(5):575-86.

69. Armstrong AJ, Halabi S, Healy P, Alumkal JJ, Winters C, Kephart J, et al. Phase II trial of the PI3 kinase inhibitor buparlisib (BKM120) with or without enzalutamide in men with metastatic castration resistant prostate cancer. Eur J Cancer. 2017;81:228-36.

70. Statz CM, Patterson SE, Mockus SM. mTOR inhibitors in castration-resistant prostate cancer: a systematic review. Target Oncol. 2017;12(1):47-59.

71. de Bono JS, De Giorgi U, Rodrigues DN, Massard C, Bracarda S, Font A, et al. Randomized phase II study evaluating akt blockade with ipatasertib, in combination with abiraterone, in patients with metastatic prostate cancer with and without PTEN Loss. Clin Cancer Res. 2019;25(3):928-36.

72. Le DT, Uram JN, Wang H, Bartlett BR, Kemberling H, Eyring AD, et al. PD-1 blockade in tumors with mismatch-repair deficiency. N Engl J Med. 2015;372(26):2509-20.

73. Le DT, Durham JN, Smith KN, Wang H, Bartlett BR, Aulakh LK, et al. Mismatch repair deficiency predicts response of solid tumors to PD-1 blockade. Science. 2017;357(6349):409-13.

74. Abida W, Cheng ML, Armenia J, Middha S, Autio KA, Vargas HA, et al. Analysis of the prevalence of microsatellite instability in prostate cancer and response to immune checkpoint blockade. Jama Oncol. 2018. https://doi.org/10.1001/jamaoncol.2018.5801.

75. Antonarakis ES, Shaukat F, Isaacsson Velho P, Kaur H, Shenderov E, Pardoll DM, et al. Clinical features and therapeutic outcomes in men with advanced prostate cancer and DNA mismatch repair gene mutations. Eur Urol. 2019;75(3):378-82.

76. Wu YM, Cieslik M, Lonigro RJ, Vats P, Reimers MA, Cao X, et al. Inactivation of CDK12 delineates a distinct Immunogenic class of advanced prostate cancer. Cell. 2018;173(7):1770-82 e14.

77. Isaacsson Velho P, Qazi F, Hassan S, Carducci MA, Denmeade SR, Markowski MC, et al. efficacy of radium-223 in bone-metastatic castration-resistant prostate cancer with and without homologous repair gene defects. Eur Urol. 2019;76(2):170-6.

78. Crumbaker M, Emmett L, Horvath LG, Joshua AM. Exceptional response to 177Lutetium prostate-specific membrane antigen in prostate cancer harboring DNA repair defects. JCO Precis Oncol. 2019; https://doi.org/10.1200/PO.18.00237. 6 februari. DOI:.

79. McNeel DG, Eickhoff JC, Wargowski E, Zahm C, Staab MJ, Straus J, et al. Concurrent, but not sequential, PD-1 blockade with a DNA vaccine elicits anti-tumor responses in patients with metastatic, castration-resistant prostate cancer. Oncotarget. 2018;9(39):25586-96.

Minke Smits fellow medical oncology

Winald Gerritsen consultant medical oncology

Niven Mehra consultant medical oncology 
Hier staat een advertentie.

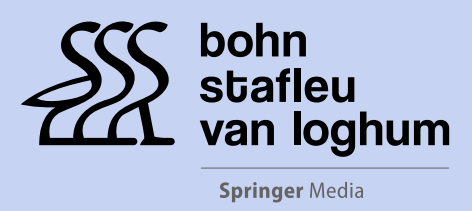

Houten 2019 
Hier staat een advertentie.

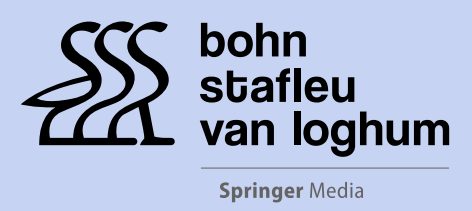

Houten 2019 